\title{
Natureza da ciência: o que os pesquisadores brasileiros discutem?
}

Title: expressing the essence of the idea or main topic in english

\author{
Carla Krupczak ${ }^{1}$ \\ Joanez Aparecida Aires ${ }^{2}$
}

\section{Resumo}

No ensino de Ciências é consenso que um tópico importante deste é a abordagem sobre a Natureza da Ciência (NdC), esta visa discutir sobre a construção do conhecimento científico, desmistificando estereótipos sobre a Ciência e o trabalho do cientista. Considera-se que um melhor entendimento sobre o desenvolvimento científico e tecnológico pode contribuir para a formação de cidadãos que tomam decisões mais fundamentadas sobre Ciência e Tecnologia. Tendo em vista a relevância do tema, estudos sobre NdC vêm aumentando, gerando trabalhos que analisam as tendências dessa temática em artigos, todavia, há carência de trabalhos que se debrucem sobre as teses e dissertações brasileiras. Nesse sentido, o objetivo desta pesquisa é mapear como estão distribuídos esses estudos sobre $\mathrm{NdC}$ no Brasil, bem como analisar as tendências destes, em relação aos objetivos das pesquisas. A investigação é do tipo estado do conhecimento, de natureza quantiqualitativa. A constituição dos dados foi realizada no Banco de Teses e Dissertações da CAPES e as análises se deram usando a Análise de Conteúdo. Foram encontrados 233 trabalhos, com maior produtividade a partir de 2008. As pesquisas concentram-se na região sudeste do país, em instituições públicas e os temas mais estudados foram estratégias didáticas e concepções sobre $\mathrm{NdC}$.

Palavras chave: Natureza da Ciência; Educação em Ciências no Brasil.

\section{Abstract}

In science teaching it is agreed that an important topic of this is the approach on the Nature of Science (NOS), this aims to discuss the construction of scientific knowledge, demystifying stereotypes about science and the work of the scientist. It is considered that a better understanding of scientific and technological development can contribute to the formation of citizens who make more informed decisions about Science and Technology. Considering the relevance of the topic, the studies about NOS are increasing, generating works that analyze the tendencies of this topic in articles, however, there is a shortage of papers that focus on Brazilian theses and dissertations. In this sense, the objective of this research is to map how these studies about NOS in Brazil are distributed, as well as to analyze the trends of these, in relation to the research objectives. The research is of the knowledge state type, of a quantiqualitative nature. The composition of the data was done in the Bank of Thesis and Dissertations of CAPES and the analyzes were done using Content Analysis. A total of 233 studies were found, with higher productivity since 2008. Research is concentrated in the

\footnotetext{
${ }^{1}$ Universidade Federal do Paraná | carlak.quim@gmail.com

${ }^{2}$ Universidade Federal do Paraná | joanez.ufpr@gmail.com
} 
southeastern region of the country, in public institutions and the most studied subjects were didactic strategies and conceptions about NOS.

Keywords: Nature of Science; Science Education in Brazil.

\section{Introdução}

No mundo contemporâneo, marcado pela Ciência e tecnologia, é de suma importância um melhor entendimento sobre a construção do conhecimento científico por parte dos cidadãos. Tendo em vista esta premissa, o volume de estudos sobre NdC vem aumentando, o que nos leva a considerar que a organização e sistematização destes são importantes, uma vez que, além de possibilitar conhecer as tendências do que já foi investigado sobre o tema, pode ainda orientar e estimular novos trabalhos. Nesse sentido, o objetivo desta pesquisa é mapear como estão distribuídas as teses e dissertações brasileiras sobre $\mathrm{NdC}$ no Brasil, bem como analisar as tendências destas, em relação aos objetivos das pesquisas.

Alguns trabalhos que também realizaram estudos sobre as tendências na pesquisa sobre NdC serviram de base para esta investigação (LEDERMAN, 1992; HARRES, 1999; AZEVEDO; SCARPA, 2017). Lederman (1992) realizou uma revisão onde analisou os trabalhos mais citados nos anos que antecederam a publicação do artigo. $O$ autor encontrou que as investigações dividiam-se em quatro tópicos de interesse: avaliação das concepções de estudantes sobre a NdC; desenvolvimento e uso de currículos que abordam a NdC; as concepções de $\mathrm{NdC}$ de professores e a relação com a prática em sala; tentativas de melhorar a concepção de professores acerca da NdC. Lederman (1992) destacou que: (i) os alunos e professores de Ciências não tinham concepções adequadas da construção do conhecimento científico, (ii) a formação docente não relacionava aspectos da $\mathrm{NdC}$ e (iii) melhorar as concepções dos professores estava bastante associado ao uso da História da Ciência.

Harres (1999) fez uma revisão das pesquisas internacionais, focando em particular nas concepções dos professores e na formação destes. O autor constatou que a maioria dos trabalhos identificou nos professores visões empírico-indutivistas, centradas na observação e no método científico. Além disso, estas visões de Ciência refletiam-se na maneira de perceber o ensino de Ciências. A partir de tais visões, este ensino é visto como baseado no raciocínio lógico, nas explicações que pressupõem a existência de verdades na Ciência e também desconsidera o conhecimento prévio do aluno, o que é coerente com a concepção empírico-indutivista da $\mathrm{NdC}$.

Azevedo e Scarpa (2017) analisaram artigos de revistas classificadas de A1 até B3 com foco em Educação ou Ensino explícito em seus sites. Seguindo os critérios do PRISMA elas encontraram 396 artigos publicados até fevereiro de 2015, sendo mais de metade trabalhos que levantavam as concepções de $\mathrm{NdC}$ de grupos. As autoras também destacam a falta de revisões sistemáticas das pesquisas cujo escopo é a $\mathrm{NdC}$.

Porém, nenhuma dessas pesquisas analisou as teses e dissertações brasileiras, também não focaram na distribuição desses trabalhos. E é nesse sentido que consideramos que esta investigação possa trazer alguma contribuição para a área, em especial para entendermos como os pesquisadores brasileiros vêm discutindo a NdC. 


\section{Natureza da ciência: considerações teóricas}

Um dos objetivos do ensino de Ciências é formar cidadãos críticos, preparados para agir no mundo (MOURA, 2014). Para isso é preciso não apenas ensinar Ciência, mas também sobre Ciência, sobre como ocorre o desenvolvimento científico, o que é conhecido como Natureza da Ciência. Segundo Moura (2014):

De uma perspectiva bem ampla e geral, podemos dizer que a natureza da Ciência envolve um arcabouço de saberes sobre as bases epistemológicas, filosóficas, históricas e culturais da Ciência. Compreender a natureza da Ciência significa saber do que ela é feita, como elaborá-la, o que e por que ela influencia e é influenciada (p. 33).

Já Lederman (1992) aponta que a NdC "geralmente se refere aos valores e suposições inerentes ao desenvolvimento do conhecimento científico" (LEDERMAN, 1992, p. 331, tradução nossa) dando mais ênfase para a questão dos valores envolvidos na Ciência. Forato, Pietrocola e Martins (2011) enfatizam que a inserção de conteúdos sobre a NdC é necessária para construir diálogos entre os conhecimentos científicos e as habilidades de um cidadão do século XXI. Isso não significa que os conteúdos técnicos devem ser negligenciados, mas que se deve buscar uma educação em, sobre e pela Ciência.

Para promover o entendimento sobre a $\mathrm{NdC}$ é preciso portanto, inserir ao longo do trabalho com os conteúdos específicos, aspectos sobre a construção da Ciência, para que o ensino não seja descontextualizado e os alunos compreendam o processo de construção do conhecimento, as características do trabalho científico e suas diversas particularidades, adquirindo a capacidade de tomar decisões fundamentadas e contribuir em debates sociais, onde o grupo científico é uma das vozes da sociedade (MOURA, 2014; GALVÃO; REIS; FREIRE, 2011). Segundo Reis e Galvão (2006) desenvolver uma imagem real da Ciência, por meio da filosofia e história, pode melhorar a compreensão sobre a relação entre esta e a sociedade, diminuindo tendências positivistas. Tendo em vista que, em sociedades desenvolvidas, cientifica e tecnologicamente, o cidadão só consegue exercer a democracia se entender o que ocorre no meio onde vive.

Tais argumentos se ancoram em pesquisas que apontam que os estudantes e até professores apresentam concepções deformadas sobre Ciência, gerando desinteresse e, por vezes constituindo-se em obstáculo para a aprendizagem (PRAIA; PÉREZ; VILCHES, 2007). De acordo com Reis e Galvão (2009) as pessoas, de modo geral, costumam imaginar que a Ciência é um caminho em linha reta, de simples acumulação de conhecimentos, sem nenhum tipo de controvérsia, influência social e que sempre representa a verdade e a confiabilidade. Além disso, é apresentada pelos meios de comunicação como complicada, realizada por algumas poucas pessoas geniais e às vezes envolvida com práticas pouco éticas, reforçando o assombro e a desconfiança que a distancia dos cidadãos. Essa visão rígida adquirida na escola é corroborada pela mídia, que é para a maioria da população, a única fonte de informações sobre as inovações na Ciência e Tecnologia. Desse modo, para a maioria das pessoas, a Ciência é apenas o que se vê na imprensa.

Pérez et al. (2001) argumentam que "faria sentido pensar que, tendo nós uma formação científica (...) e sendo nós professores de Ciências, deveríamos ter adquirido (...) uma imagem adequada do que é a construção do conhecimento científico" (p. 125). Porém, diversos trabalhos mostram que isso não condiz com a realidade e muitos professores e licenciandos, ainda associam Ciência a um método científico único e a visões empírico- 
indutivistas (LEDERMAN, 1992; PÉREZ ET AL., 2001; FERNÁNDEZ ET AL., 2002; SCHEID; FERRARI; DELIZOICOV, 2007). Os próprios cientistas têm visões incrivelmente diversas sobre a NdC (IRZIK; NOLA, 2011).

Mesmo não existindo consenso sobre o que é a $\mathrm{NdC}$ existem trabalhos bem conceituados na literatura que apontam o que deve ser evitado e o que pode ser utilizado no ensino. Afinal, durante todo o século XX diversos epistemólogos, a exemplo de Popper, Feyerabend, Bachelard e Khun, têm defendido que a visão positivista da Ciência não corresponde a realidade da construção do conhecimento científico. Em 2001 Pérez et al. categorizaram 7 visões, por eles consideradas deformadas de Ciência, as quais são corroboradas por vários autores. São elas:

1) Empírico-indutivista: é a mais difundida e baseia-se na ideia de que a observação e a experiência são neutras e não são afetadas pelas teorias já existentes. Também propaga o conceito de descoberta, frequente na imprensa e meios de comunicação (PÉREZ ET AL., 2001).

2) Rígida: apoia-se no método científico, conjunto de processos quantitativos e de controle rigoroso, que garante resultados inquestionáveis (PÉREZ ET AL., 2001).

3) Aproblemática e ahistórica: omite-se o contexto histórico, a pergunta que deu origem ao conhecimento já existente, as limitações desse saber e as perspectivas que ele abre, dificultando o entendimento do processo científico (PÉREZ ET AL., 2001).

4) Exclusivamente analítica: ressalta a divisão dos estudos, ignorando as tentativas de criação de teorias unificadoras e dos problemas-ponte, que ligam áreas diferentes (PÉREZ ET AL., 2001).

5) Acumulativa de crescimento linear: aponta a construção dos saberes como uma linha contínua de simples acumulação, esquecendo-se das contradições, crises e controvérsias científicas que ocorrem durante o processo (PÉREZ ET AL., 2001).

6) Individualista e elitista: acredita que o conhecimento é fruto do trabalho de um único gênio, desprezando o trabalho coletivo. Além disso, a Ciência é apresentada como exclusividade de umas poucas pessoas dotadas de grande inteligência, na sua maioria homens de classes altas (PÉREZ ET AL., 2001).

7) Socialmente neutra: a Ciência e o cientista são encarados como neutros, sem influências da sociedade. As implicações do desenvolvimento científico e tecnológico são menosprezadas (PÉREZ ET AL., 2001).

Pérez et al. (2001) destacam que essas visões deformadas não são únicas e nem isoladas, elas podem aparecer juntas em diversos contextos, reforçando estereótipos no ensino de ciências seja por ação ou omissão. A pesquisa destes autores demonstrou que os professores e até cientistas podem apresentar imagens de Ciência próximas do senso comum. Desse modo, questionam-se quais seriam as visões adequadas sobre $\mathrm{NdC}$. Existem duas principais vertentes de pensamento: a dos aspectos consensuais e o conceito de semelhança familiar (family resemblance no original em inglês).

A linha dos aspectos consensuais é defendida por autores como Pérez et al. (2001) e corresponde a uma lista de princípios objetivos sobre o que ocorre na construção do conhecimento. Em seus trabalhos eles listam cinco aspectos tidos como consensuais. São:

1) Não existe um método científico: os pesquisadores concordam que não existem regras universais que façam a Ciência, existem diversas metodologias (PÉREZ ET AL., 2001). 
2) A Ciência é dinâmica, mutável e objetiva explicar a natureza: os autores argumentam que o conhecimento não é estático, está sempre em mudança buscando explicar o que acontece no mundo (PÉREZ ET AL., 2001).

3) A Ciência é influenciada pelo seu contexto cultural, social, político: nesse aspecto evidencia-se que a Ciência não é neutra e o cientista se deixa influenciar por suas crenças, adquiridas no contexto em que vive (PÉREZ ET AL., 2001).

4) Teorias não são consequência de observação e experimentos: este aspecto perpassa a concepção de que toda teoria advém de um experimento que a prova, o que é impossível considerando que as teorias são sempre provisórias (PÉREZ ET AL., 2001).

5) Cientistas são humanos comuns: isso significa que eles cometem erros, sofrem influencia do que está ao seu redor, usam de crenças e expectativas para formular hipóteses (PÉREZ ET AL., 2001).

Porém, esses não são os únicos aspectos consensuais presentes na literatura para a descrição da NdC. Azevedo e Scarpa (2017) encontraram, durante uma revisão sistemática dos artigos publicados até 2015 sobre o tema, 25 aspectos considerados consensuais presentes nas pesquisas. Isto mostra que existe um debate na área para definir o que deve ser elemento obrigatório na lista dos aspectos consensuais para a discussão da construção do conhecimento científico na educação básica.

Já a linha da semelhança familiar surgiu como uma crítica à teoria dos aspectos consensuais, pois seus defensores, como Irzik e Nola (2011), acreditam que a Ciência é dinâmica demais para ser definida por alguns pontos estáticos. Consideram que a ideia dos aspectos consensuais leva o aluno a acreditar que a NdC é imutável historicamente, quando na verdade ela está sempre evoluindo. Também criticam o fato de que essa lista de aspectos pode gerar más compreensões, os alunos podem considerar, por exemplo, que o fato do conhecimento científico ser provisório significa que ele não é confiável. Além disso, a lista de aspectos consensuais faz surgir alguns questionamentos, por exemplo: se a Ciência é social e culturalmente afetada porque produz saberes que funcionam em várias sociedades? A influência da sociedade na Ciência é boa ou ruim? Como identificar as ruins e eliminá-las? (IRZIK; NOLA, 2011).

O conceito de semelhança familiar baseia-se na ideia de características em comum. Desse modo, os pesquisadores definem quatro categorias de semelhança familiar. As áreas da Ciência podem compartilhar categorias e ser diferentes em outras, o que faz com que elas não sejam idênticas, mas sejam caracterizadas como Ciência (IRZIK; NOLA, 2011). As categorias de semelhança familiar são:

1) Atividades: as áreas diferenciam-se no tipo de atividade, que pode ser de observação, de uso de equipamentos e de técnicas experimentais ou teóricas (IRZIK; NOLA, 2011).

2) Metodologias: não existe um método científico universal, mas cada área usa uma metodologia específica. A atividade científica segue uma lógica que a torna racional e faz os dados confiáveis (IRZIK; NOLA, 2011).

3) Objetivos e valores: cada área tem uma finalidade diferente (IRZIK; NOLA, 2011).

4) Produtos: os resultados são diferentes, podem ser teorias, dados experimentais, hipóteses, entre outros (IRZIK; NOLA, 2011).

Porém é preciso lembrar que: 
A definição acerca do que é natureza da Ciência não parece uma tarefa simples. Pela análise das duas concepções acima, podemos perceber similaridades e diferenças notáveis. (...) destacamos que estas são apenas duas visões, pois um olhar mais apurado para o que os filósofos e os historiadores da Ciência ou os educadores dizem, por exemplo, pode subsidiar inúmeras concepções diferentes, que não necessariamente se assemelhariam com as duas discutidas anteriormente (MOURA, 2014, p. 36).

Assim, é importante frisar que para discutir a $\mathrm{NdC}$ não existe um único método universal para defini-la ou uma única forma de abordá-la. Mas, isso não é resolvido deixando de falar das características do desenvolvimento científico e sim se discutindo para evitar deformações e simplismos (PRAIA; PÉREZ; VILCHES, 2007).

\section{Metodologia}

Esta pesquisa é de natureza quantiqualitativa e se caracteriza como um trabalho do tipo estado do conhecimento. Segundo Flick (2009) a ligação das metodologias quantitativas com as qualitativas se faz bastante útil nas práticas de pesquisa, pois "as diferentes perspectivas metodológicas complementam-se para a análise de um tema, sendo este processo compreendido como a compensação complementar das deficiências e dos pontos obscuros de cada método isolado" (p. 43). Assim, optamos por utilizar dados quantitativos e análises qualitativas.

Com relação ao tipo de metodologia usada, segundo Romanowski e Ens (2006) trabalhos do estado da arte:

(...) recebem esta denominação quando abrangem toda uma área do conhecimento, nos diferentes aspectos que geraram produções. Por exemplo: para realizar um 'estado da arte' sobre 'Formação de Professores no Brasil' não basta apenas estudar os resumos de dissertações e teses, são necessários estudos sobre as produções em congressos na área, estudos sobre as publicações em periódicos da área. O estudo que aborda apenas um setor das publicações sobre o tema estudado vem sendo denominado de 'estado do conhecimento' (p. 3940).

Assim, esta pesquisa não é um estado da arte, porque não analisa toda a produção da área de Educação em Ciências sobre NdC, o foco está apenas nas teses e dissertações (TD), sendo um trabalho do tipo estado do conhecimento. Optamos pela análise apenas de TD porque consideramos que estas são representativas das pesquisas realizadas no Brasil. Além disso, a maioria das TD gera artigos em revistas científicas e trabalhos em anais de eventos, portanto seria redundante analisar estes trabalhos.

Ademais, Palanch e Freitas (2015) salientam que "ainda há poucos autores e pesquisadores que se dedicam à realização de amplas pesquisas do tipo Estado da Arte e, menos ainda, aqueles que escrevem e teorizam sobre esse tipo de pesquisa" (p. 785). As pesquisas do estado da arte e estado do conhecimento são de caráter bibliográfico e buscam mapear uma temática, encontrando as tendências na produção do conhecimento. A evolução da Ciência exige que de tempos em tempos se organize as informações 
existentes, buscando as lacunas a pesquisar e as relações entre resultados aparentemente autônomos (FERREIRA, 2002).

Nesta pesquisa a constituição dos dados para este estado do conhecimento foi realizada no Banco de Teses e Dissertações da CAPES. Buscaram-se trabalhos que tivessem em seus títulos, resumos ou palavras-chaves o termo "Natureza da Ciência", sem restrições de ano de publicação. Dentre todas as opções foram consideradas apenas as pesquisas que eram de Programas de Pós-graduação (PPG) das áreas de avaliação Educação ou Ensino e os que se enquadravam como investigações de mestrado acadêmico ou profissional e doutorado. As pesquisas foram classificadas por descritores gerais: grau de titulação, ano de publicação, instituição e região geográfica. Esses descritores foram usados para a identificação inicial da produção no tema.

Para a exploração das TD utilizamos a Análise de Conteúdo (BARDIN, 2004) como metodologia. Esta é composta de três etapas: pré-análise, exploração e inferência. Na primeira realiza-se a leitura flutuante, escolha e preparação dos materiais. Na segunda definem-se as unidades de registro e as unidades de contexto, das quais surgem as categorias que apresentam características em comum. E na última etapa interpretam-se as categorias, relacionando com o referencial teórico (BARDIN, 2004).

Do agrupamento das unidades de registro emergiram quatro categorias: A - Estratégias Didáticas, $B$ - Concepções da NdC, que se divide em três subcategorias (concepções dos alunos, dos professores e dos materiais), C - Formação de Professores e D - Currículo. Estas categorias estão em consonância com as descritas por Lederman (1992): avaliação das concepções de estudantes sobre a NdC; desenvolvimento e uso de currículos que abordam a $\mathrm{NdC}$; as concepções de NdC de professores e a relação com a prática em sala e tentativas de melhorar a concepção de professores acerca da NdC. Estas relações estão evidenciadas na Figura 1. Algumas das TD foram classificadas dentro de duas categorias.

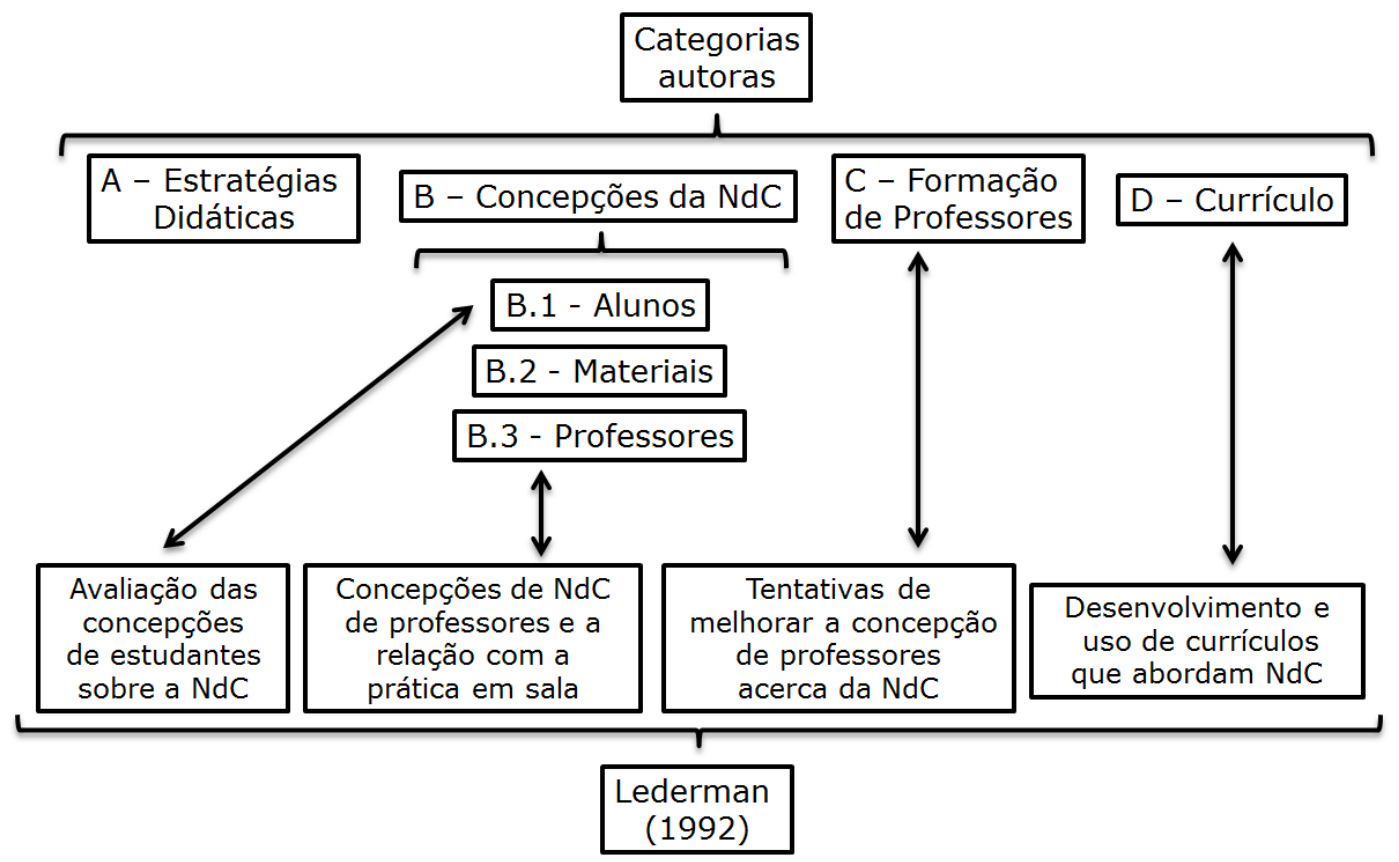

Figura 1: a) Correlação entre as categorias que emergiram da análise das TD e as categorias de Lederman (1992). 


\section{O estado do conhecimento da natureza da ciência}

Foram encontrados 233 trabalhos no Banco de Teses e Dissertações da CAPES com o termo "Natureza da Ciência", que eram de programas avaliados como de Educação ou Ensino. A distribuição destes pode ser verificada na Figura 2. Quanto ao descritor geral grau de titulação temos que das 233 investigações 149 eram dissertações de mestrado acadêmico, 25 de mestrado profissional e 59 teses de doutorado. Em relação ao ano de publicação verificamos que a primeira dissertação brasileira que aborda o tema é de 1997. Porém, a primeira tese com o termo "Natureza da Ciência" em seu título é de 1999, cujo autor é João Batista Siqueira Harres e chama-se "Concepções de professores sobre a Natureza da Ciência". Os dois trabalhos anteriores sobre o tema não o traziam explícito no título, apenas nas palavras-chave e resumo. Percebe-se que até 2007 o número de pesquisas era sempre menor que cinco, indicando pouco interesse pelo assunto. A partir de 2008 o número de investigações aumenta gradativamente e em 2017 atinge o auge com 39 TD. Esse fato revela que o tema ganhou importância no Brasil a partir desse período. Análise dos artigos nacionais e internacionais publicados até 2014 realizada por Azevedo e Scarpa (2017) mostra que as pesquisas internacionais sobre NdC aumentaram em 1997, ano em que o Brasil começou a tratar o tema, indicando a influência internacional.

Quanto à instituição os trabalhos estão distribuídos em 42 IES diferentes. Destas 38 são públicas, três são particulares e uma é comunitária. Essa diferença significativa entre pesquisas realizadas em IES públicas e privadas mostra como as instituições públicas são importantes no desenvolvimento científico do país, uma vez que estas concentram quase toda a pesquisa do Brasil. As quatro instituições com mais pesquisas foram USP (33), Cefet/RJ (26), UFRN (15) e UFBA (13). Essas têm grupos de pesquisa específicos sobre o tema, por isso geram mais trabalhos.

A distribuição geográfica dos trabalhos por região está indicada na Figura 3. A região sudeste concentra mais da metade das pesquisas (51,1\%), principalmente por conta das contribuições de USP, Cefet/RJ e UFMG. Esses dados estão de acordo com o Relatório de Avaliação 2013-2016 quadrienal da CAPES para a área de avaliação de Ensino (CAPES, 2017). A distribuição das matrículas em PPG pelo Brasil (Figura 4) mostra que o maior número de matrículas está na região sudeste. As regiões sul e nordeste apresentam praticamente a mesma produção de pesquisas sobre $\mathrm{NdC}$ e números próximos de matrículas em PPG. Já o norte e o centro-oeste têm menos alunos e por consequência menos pesquisas, não sendo por isso menos importantes ou de menor qualidade. Essa distribuição desigual de PPG é preocupante e a análise e discussão dos motivos e consequências dessas diferenças são importantes, mas não serão feitas aqui por não entrarem no escopo inicial dessa etapa do trabalho. 


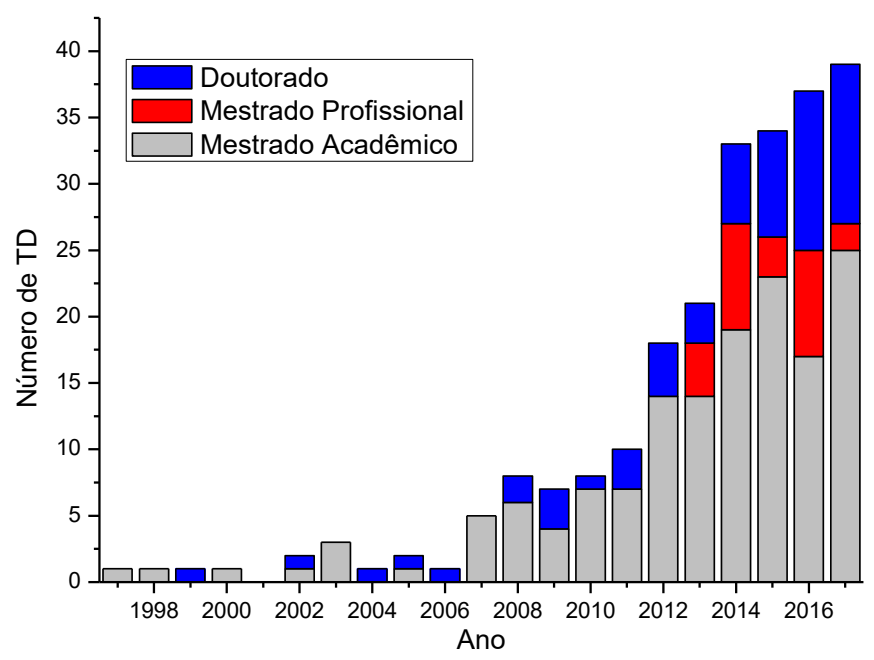

Figura 2: Número de TD encontradas no Banco de Teses e Dissertações da CAPES sobre NdC. Fonte: as autoras.

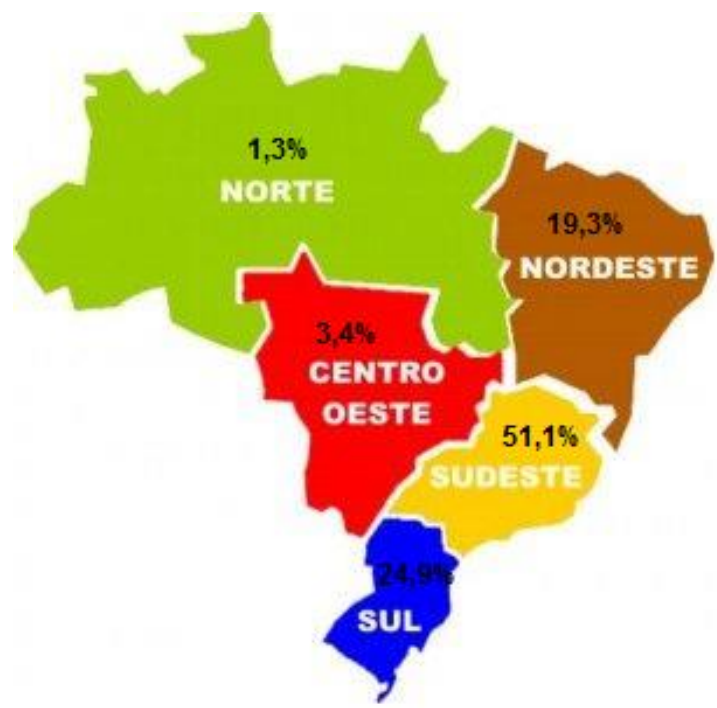

Figura 3: Distribuição regional dos trabalhos sobre Natureza da Ciência. Fonte: as autoras.

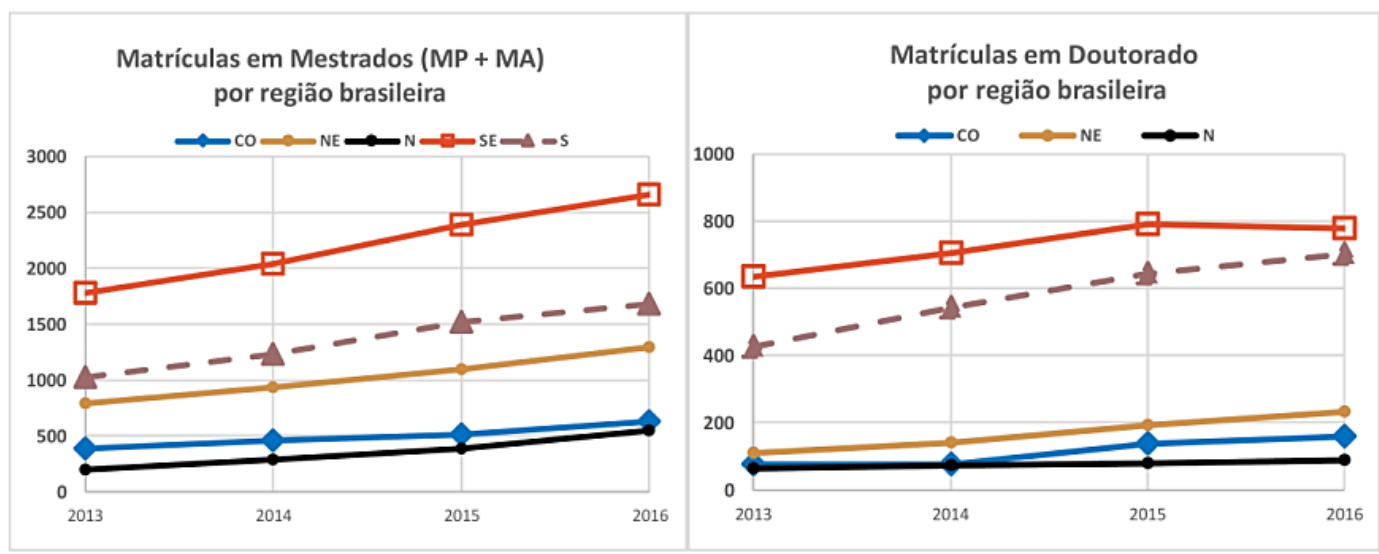

Figura 4: Crescimento anual do número de matrículas de Mestrado (somadas as de Mestrado Acadêmico e Profissional) e de Doutorado, oferecidas pelos Programas de Pós-Graduação da Área de Ensino por região brasileira. Fonte: CAPES, 2017, p. 12. 
O passo seguinte da investigação envolveu a análise das pesquisas pela Análise de Conteúdo, baseada em Bardin (2004). O agrupamento das unidades de registro encontradas produziram quatro categorias: A) Estratégias Didáticas, B) Concepções da NdC (subdividida em B.1) Alunos, B.2) Materiais, B.3) Professores), C) Formação de Professores e D) Currículo. A distribuição das TD dentro dessas categorias está representada na Figura 5.

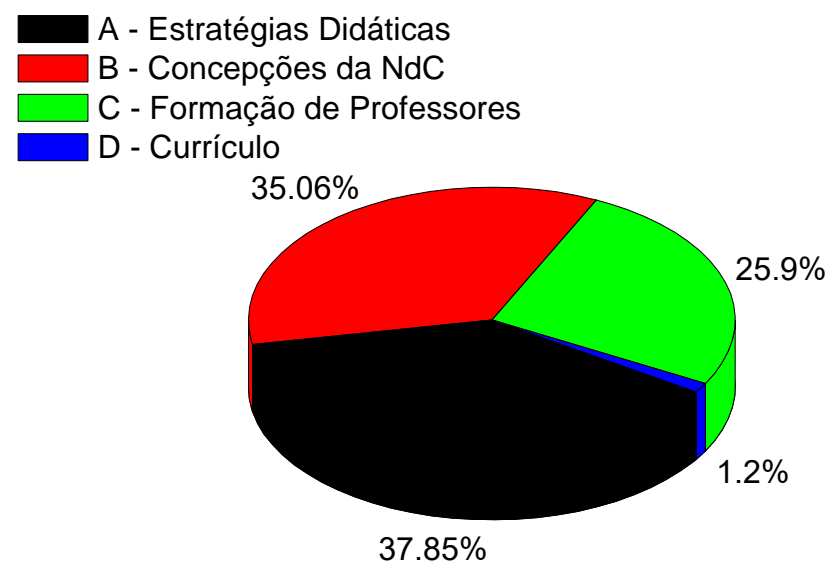

Figura 5: Distribuição dos títulos das teses e dissertações nas quatro categorias advindas da análise de conteúdo realizada. Fonte: as autoras.

É relevante notar que as categorias construídas estão em consonância com a revisão de Lederman (1992), mas com alguns avanços. O autor observou que as pesquisas da sua época (até 1992) se enquadravam em quatro categorias: avaliação das concepções de estudantes sobre a NdC; desenvolvimento e uso de currículos que abordam a NdC; as concepções de NdC de professores e a relação com a prática em sala e tentativas de melhorar a concepção de professores acerca da NdC (LEDERMAN, 1992). As categorias de Lederman seguem uma sequência histórica. Segundo o autor, as primeiras investigações sobre a construção do conhecimento científico eram do tipo que buscavam identificar as concepções que os estudantes do ensino básico tinham da NdC. Os resultados mostraram que a maioria dos alunos tinha uma visão estereotipada e positivista da Ciência. Ou seja, entendiam o conhecimento científico como verdadeiro e estável, acreditavam no uso do método científico, viam a Ciência como neutra e o cientista como um gênio que trabalha isolado de tudo, visões que muitas vezes ainda persistem hoje (LEDERMAN,1992; PÉREZ ET AL., 2001; LEDERMAN ET AL., 2002). Com estas constatações os pesquisadores começaram a desenvolver currículos que abordassem a NdC. Porém, o resultado não foi o esperado e as concepções não mudaram (LEDERMAN, 1992). Foi então que os investigadores perceberam que existia outro fator que fazia com que os currículos preparados para discutir a $\mathrm{NdC}$ não fossem suficientes para alterar as visões dos estudantes: os professores. Começaram então, os estudos para entender como os docentes veem a construção do conhecimento científico e estes mostraram que as visões dos professores eram tão positivistas quanto as dos alunos. Assim, iniciaram as pesquisas acerca da formação de professores, com vistas a levar as discussões sobre a NdC para estes docentes (LEDERMAN, 1992).

As categorias emergentes desta pesquisa seguem lógica parecida. A diferença é que hoje a área avançou e, além dos tipos de pesquisas anteriormente descritas, realizam-se estudos com o intuito de criar sequências e atividades didáticas para auxiliar os docentes (categoria A) e analisam-se materiais de uso pedagógico e de divulgação científica 
(subcategoria B.2). Assim, atualmente a maior parte da TD (37,85\%) aborda a produção de sequências didáticas e atividades para sala de aula. Um exemplo de dissertação da categoria A é "Inércia e Natureza da Ciência no Ensino de Física: uma sequência didática centrada no desenvolvimento histórico do conceito de inércia", em que os termos sublinhados correspondem a uma das unidades de registro da categoria (em todos os exemplos dados as unidades de registro estão sublinhadas).

As TD da categoria B, Concepções da NdC (35,6 \%), são subdivididas em 3 subcategorias e constituem trabalhos que buscam identificar a presença ou não das concepções de Ciência como as descritas por Pérez et al. (2001) com base na teoria dos aspectos consensuais ou da semelhança familiar (IRZIK; NOLA, 2011). São investigações que entrariam na primeira e terceira categorias de Lederman (1992), que são avaliação das concepções de estudantes sobre a NdC e as concepções de $\mathrm{NdC}$ de professores e a relação com a prática em sala. Para captar as concepções de grupos de pessoas existem diversos tipos de instrumentos, na sua maioria questionários. Um dos instrumentos mais conhecidos é o "Views of Nature of Science Questionnaire" ou VNOS, o qual tem várias versões (LEDERMAN; O'MALLEY, 1990; ABD-EL-KHALICK; BELL; LEDERMAN, 1998; LEDERMAN ET AL., 2002). De modo geral, consiste em um questionário com questões abertas seguido de entrevista semiestruturada.

Na subcategoria B.1, Concepções da NdC de Alunos, estão 13,64\% das TD da categoria $\mathrm{B}$ e compõem pesquisas onde é investigada a visão dos estudantes sobre a NdC. Como exemplo temos o trabalho "Concepções de estudantes do ensino fundamental acerca da Investigação Científica e da Natureza da Ciência". Na subcategoria B. 2, Concepções da NdC de Materiais, encontram-se 54,54\% das investigações da categoria B. São pesquisas que analisam as concepções da NdC presentes em livros didáticos, filmes e vídeos, materiais de divulgação científica, entre outros. Um exemplo é a dissertação "Os aspectos da Natureza da Ciência nos textos sobre evolução biológica na Revista Scientific American Brasil". A subcategoria B.3, Concepções da NdC de Professores, abarcou 31,38\% das TD da categoria $B$, contendo trabalhos que buscam entender as concepções que os professores têm da construção do conhecimento científico. A pesquisa "Análise das concepções de professores de biologia em formação inicial acerca da relação entre ciência e valores" é um exemplo desta subcategoria.

A categoria C, Formação de Professores, corresponde a 25,90\% dos trabalhos atuais. Esta relaciona-se com a última categoria de Lederman (1992), que é tentativas de melhorar a concepção de professores acerca da NdC. Depois que os estudos mostraram que não era o currículo o principal fator para a compreensão dos alunos da NdC, o foco voltou-se para a variável professor (LEDERMAN, 1992). Assim, estas pesquisas buscam maneiras de formar adequadamente os docentes de Ciências nesse aspecto. Afinal pesquisas da literatura mostram que a maioria dos docentes tem concepções inadequadas da construção do conhecimento científico (LEDERMAN,1992; ABD-EL-KHALICK; LEDERMAN, 2000; PÉREZ ET AL., 2001; FERNANDÉZ ET AL., 2002; SCHEID; FERRARI; DELIZOICOV, 2007). As experiências que os docentes têm durante sua formação inicial e continuada podem representar grande influência na forma como o professor irá estruturar suas práticas docentes. Desse modo, se o mesmo não tem concepções adequadas sobre a NdC estas serão visíveis em suas aulas. Segundo Forato, Pietrocola e Martins (2011, p. 30) "a concepção que se tem sobre a Ciência estará sempre refletida, explícita ou implicitamente, em todas as iniciativas educacionais que 
digam respeito à Ciência, desde a seleção e abordagem de conteúdos, até as metodologias educacionais utilizadas". Além disso, os autores colocam que:

[...] não é possível separar essas quatro instâncias: (i) a visão que se tem da Ciência; (ii) a concepção sobre os processos históricos e sociais de sua construção; (iii) os elementos que guiam a seleção dos saberes escolares; e (iv) os pressupostos que guiam os métodos de seu ensino e aprendizagem (FORATO; PIETROCOLA, MARTINS, 2011, p. 30).

Porém, não basta formação, Lederman (1992) afirma que mesmo que o professor entenda a Ciência de forma adequada, se o mesmo não traduzir isto em ações na sala, acaba não influenciando as visões dos estudantes e é nesse sentido que as pesquisas das categorias A e B são relevantes. Um exemplo de trabalho da categoria C é "Formação continuada de professores em Natureza da Ciência e Tecnologia com enfoque nas competências científicas".

Já a segunda categoria de Lederman (1992), desenvolvimento e uso de currículos que abordam a $N d C$, hoje representa a categoria $D$ e é a minoria das pesquisas, apenas 1,20\%. Esse fato pode ser decorrente das conclusões de análises anteriores, que mostraram que o currículo não era o principal fator determinante no entendimento da $\mathrm{NdC}$, como já discutido, tal determinante era o professor (Lederman, 1992). Um exemplo desta categoria é "História e Filosofia da Ciência nos currículos das licenciaturas em física e química da UFRN". Assim, as quatro categorias que emergiram da análise das TD são importantes para a área evoluir e alcançar todas as escolas e universidades do país.

\section{Conclusões}

Esta pesquisa teve como objetivo mapear como estão distribuídas as teses e dissertações sobre NdC no Brasil, bem como conhecer as tendências destes. Observamos que as investigações sobre $\mathrm{NdC}$ cresceram muito a partir de 2008, mostrando que a temática passou a ocupar espaço significativo na área de Ensino de Ciências. Em torno de 90\% dos trabalhos ocorreram em universidades públicas, indicando a importância dessas instituições em termos do desenvolvimento científico do país. A maior parte da produção concentra-se na região sudeste do país, onde existe maior número de PPG.

A análise dos objetivos das teses e dissertações gerou quatro categorias: A) Estratégias Didáticas, B) Concepções da NdC (subdividida em B.1) Alunos, B.2) Materiais, B.3) Professores), C) Formação de Professores e D) Currículo. Essas categorias estão em consonância com a análise feita por Lederman (1992), mas apresentaram avanços. Lederman encontrou pesquisas relativas 1) às concepções sobre a $\mathrm{NdC}$ de alunos, 2) a construção de currículos com abordagem da $\mathrm{NdC}$, 3) às concepções sobre a $\mathrm{NdC}$ de professores e a 4) formação docente. Hoje estes temas ainda são pesquisados, mas a temática avançou e pesquisam-se também concepções de NdC em materiais didáticos e de divulgação científica e propõem-se estratégias didáticas para auxiliar os professores a trabalhar com a discussão da construção do conhecimento científico.

Assim, a evolução das pesquisas na área ficou evidente e hoje o tópico mais presente nas TD é Estratégias Didáticas. Tal resultado demonstra uma sensível e positiva preocupação por parte dos pesquisadores, no sentido de prover os professores de metodologias que possam subsidiá-los em suas aulas que tenham como enfoque abordagens sobre NdC. 
Afinal, apenas a formação docente não é suficiente, pois mesmo que este entenda de forma adequada todos os aspectos que subjazem a construção do conhecimento científico, se sua prática em sala de aula não incorporar tais aspectos, os estudantes não serão levados e estimulados a refletir sobre a $\mathrm{NdC}$.

É nesse sentido que Moura (2014) nos lembra que hoje a discussão não está mais ancorada na importância de abordar a NdC, pois tal aspecto já é consenso. O desafio está justamente em pensar formas de incorporá-la na Educação em Ciências. Nesse sentido, prover os professores de formação e de estratégias didáticas é de fundamental importância, desenvolvendo ações concretas que possam subsidiar as suas ações.

Esperamos que este estudo venha a contribuir para o entendimento do estado do conhecimento das pesquisas sobre $\mathrm{NdC}$ no Brasil, bem como apresentar à comunidade as lacunas nesse campo, orientando o que ainda precisa ser feito.

\section{Referências}

ABD-EL-KHALICK, F.; LEDERMAN, N. G. Improving science teachers' conceptions of nature of science: a critical review of the literature. International Journal of Science Education, v. 22, n. 7, p. 665-701, 2000.

ABD-EL-KHALICK, F.; BELL, R. L.; LEDERMAN, N. G. The nature of Science and instructional practice: Making the unnatural natural. Science \& Education, Dordrecht, v. 82, p. 417-436, 1998.

AZEVEDO, N. H.; SCARPA, D. L. Revisão sistemática de trabalhos sobre concepções de natureza da ciência no ensino de ciências. Revista Brasileira de Pesquisa em Educação em Ciências, Belo Horizonte, v. 17, n. 2, p. 579-619, ago, 2017.

BARDIN, Laurence. Análise de conteúdo. 3. ed. Lisboa: Edições 70, 2004. 223 p.

CAPES - COORDENAÇÃO DE APERFEIÇOAMENTO DE PESSOAL DE NÍVEL SUPERIOR. Diretoria de Avaliação. Relatório de avaliação 2013-2016 quadrienal 2017. Brasília, 2017.

FERNÁNDEZ, I. et al. Visiones deformadas de la ciencia transmitidas por la enseñanza.

Enseñanza de las Ciencias, Valencia, v. 20, n. 3, p. 477-488, 2002.

FERREIRA, N. S. A. As pesquisas denominadas "estado da arte". Educação \& Sociedade, Campinas, ano XXIII, no 79, p. 257-271, ago. 2002.

FLICK, U. Pesquisa qualitativa: por que e como fazê-la. In: FLICK, U. Introdução à pesquisa qualitativa. 3 ed. Porto Alegre: Artmed, 2009, p. 20-49.

FORATO, T. C. M.; PIETROCOLA, M.; MARTINS, R de A. Historiografia e natureza da Ciência na sala de aula. Caderno Brasileiro de Ensino de Física, Florianópolis, v. 28, n. 1, p. 27-59, abr. 2011.

GALVÃO, C.; REIS, P.; FREIRE, S. A discussão de controvérsias sociocientíficas na formação de professores. Ciência \& Educação, Bauru, v. 17, n. 3, p. 505-522, 2011.

HARRES, J. B. S. Uma revisão de pesquisas nas concepções de professores sobre a natureza da ciência e suas implicações para o ensino. Investigações em Ensino de Ciências, Porto Alegre, v. 4, n. 3, p. 197-211, 1999. 
IRZIK, G.; NOLA, R. A family resemblance approach to the nature of Science for Science education. Science \& Education, v. 20, p. 591-607, 2011.

LEDERMAN, N. G. Students' and teachers' conceptions of the nature of science: a review of the research. Journal of Research in Science Teaching, v. 29, n. 4, p. 331-359, 1992.

LEDERMAN, N. G.; ABD-EL-KHALICK, F.; BELL, R. L.; SCHWARTZ, R. S. Views of nature of science questionnaire: toward valid and meaningful assessment of learners' conceptions of nature of science. Journal of Research in Science Teaching, Champaign, v. 39, n. 6, p. 497521, 2002.

LEDERMAN, N. G.; O'MALLEY, M. Students' perceptions of tentativeness in Science: Development, use, and sources of change. Science Education, v. 74, p. 225-239, 1990.

MOURA, B. A. O que é natureza da Ciência e qual sua relação com a história e filosofia da ciência? Revista Brasileira de História da Ciência, Rio de Janeiro, v. 7, n. 1, p. 32-46, 2014.

PALANCH, W. B. L.; FREITAS, A. V. Estado da arte como método de trabalho científico na área de Educação Matemática: possibilidades e limitações. Perspectivas da Educação Matemática, Campo Grande, v. 8, n. temático, p. 784-802, 2015.

PÉREZ, D. G. et al. Para uma imagem não deformada do trabalho científico. Ciência \& Educação, Bauru, v. 7, n. 2, p. 125-153, 2001.

PRAIA, J.; PÉREZ, D. G.; VILCHES, A. O papel da natureza da Ciência na educação para a cidadania. Ciência \& Educação, Bauru, v. 13, n. 2, p. 141-156, 2007.

REIS, P.; GALVÃO, C. Teaching controversial socio-scientific issues in biology and geology classes: a case study. Electronic Journal of Science Education, Fort Worth, v. 13, n. 1, p. 1-24, 2009.

REIS, P.; GALVÃO, C. O diagnóstico de concepção sobre os cientistas através da análise e discussão de histórias de ficção científica redigidas pelos alunos. Revista Electrónica de Enseñanza de las Ciencias, v. 5, n. 2, p. 213-234, 2006.

ROMANOWSKI, J. P.; ENS, R. T. As pesquisas denominadas do tipo "estado da arte" em educação. Revista Diálogo Educacional, Curitiba, v. 6, n. 19, p. 37-50, set./dez. 2006.

SCHEID, N. M. J.; FERRARI, N.; DELIZOICOV, D. Concepções sobre a natureza da ciência num curso de ciências biológicas: imagens que dificultam a educação científica.

Investigações em Ensino de Ciências, Porto Alegre, v. 12, n. 2, p. 157-181, 2007. 